\title{
EVALUATION OF PROGRESSIVE COLLAPSE SCENARIO IN STEEL FRAMED STRUCTURES WITH KNEE BRACE UNDER GRAVITY AND SEISMIC LOAD
}

\author{
Ali Parvari \\ Department of Civil Engineering, Faculty of Engineering, Khomein Branch, Islamic Azad University, \\ Khomein, Iran \\ Amir Hossein Saadatmand Bahri \\ Master of Science in Structural Engineering, Khomein Branch, Islamic Azad University, Khomein, Iran
}

\begin{abstract}
Using different technologies to bear lateral load has become so common and pervasive today. Braces in metal structures are used in different ways and with various mechanisms. One of the braces types is knee brace. By its mechanism, this kind of brace could reduce the structural damage caused by lateral load. One of damages that now threatens buildings is progressive collapse during earthquake, explosion and fire. Progressive collapse is defined as spread of local failure from one member to another which ultimately results in collapse of the entire or a substantial portion of structure. The objective of this study is to investigate the progressive collapse scenario in steel structures with knee brace. After the initial design using PERFORM-3D software, three 4, 7 and 10 storey steel buildings with knee brace were modeled. Then nonlinear static and dynamic analysis was performed and in the end potential progressive collapse was evaluated. The results evaluated the effect of push down curve, roof displacement and base shear.
\end{abstract}

Keywords: progressive collapse, KBF bracing, seismic load, nonlinear static analysis, nonlinear dynamic analysis

\section{INTRODUCTION}

Structural safety has always been a key tendency for designers of engineering projects. One of the mechanisms of structural failure that has drawn much attention in recent decades is the progressive collapse. First, one or more structural member fails for some reason and any time load is redistributed it ruins other structural elements and building is progressively destroyed [1]. Generally, buildings are not designed considering loading conditions including gas explosions, bomb explosions, and collisions of vehicles, aircraft accidents, hurricanes, tornadoes and loads like these. So it is possible that when buildings are exposed to such unusual loads they would incurred by great damage. Buildings should be designed to limit localized failure by integrating structural members, improving energy and loads redistribution (through creation of alternative routes of load transfer) and withstand unusual loads [2]. Engineering community attention for the first time was attracted to this topic after destruction of part of the Ronan Point Building in London in 1960 and then following the 11 September attacks, several standardization committees started a new effort in order to improve standards of design methods against progressive collapse [3]. After the terrorist attacks especially after what happened in the World Trade Twin Towers, assessment of potential for progressive collapse in important structures became one of the research main topics. This phenomenon can also cause severe problems in structures designed based on current regulations, during horrible earthquakes and it could even lead to the destruction of the entire structure. In other words, any weaknesses in design or implementation of the structural elements may cause the phenomenon of progressive collapse during explosion or seismic loading. To prevent progressive collapse caused by unusual loads, Canadian national regulations have set some requirements 
on designing the main elements, their connections and methods for making paths for transferring the loads. General Service Administration of America (GSA) [4] proposed a practical regulation to design buildings in order to reduce the potential of progressive collapse in federal buildings. America's Department of Defense (DOD) also presented a regulation set dedicated to some methods to design the existing DOD buildings [5].

In 2016, Wibowo and Lau offered a brief review on the phenomenon of progressive collapse in the structures. Methods and requirements of several standards to prevent progressive collapse were discussed. Constraints and advantages of analysis methods available to assess structures progressive collapse were summarized. The importance of the influence of seismic load on the structures progressive collapse behavior was also discussed. It was concluded that seismic progressive collapse of structures can be analyzed through modification of current methods [9].

Kapil Khandelwal and Sherif El-Tawil (2016) examined progressive collapse in steel braced frames designed based on seismic criteria. Two-dimensional models of ten floors of the popular braced frames including SCBF and EBF were used and then APM method was used to compare the resistance of these frames against progressive collapse. Simulations suggested that braced frames with EBF system designed for high seismic risk are less damaged by progressive collapse caused by gravity load than SCBF frames designed for moderate seismic risks. It was concluded that this is the sequence of EBF system better formability [7].

Hartanto Wibowo and Silvena Reshotkina (2016) used APM method to model progressive collapse in concrete bridges during earthquakes. Results illustrated the significant effect of progressive collapse on bridges' performance during earthquakes. Researchers also emphasized on the necessity of considering the mechanism of progressive collapse in evaluating the seismic performance of new structures and announced that this phenomenon can occur during an earthquake and is not limited to the gravity and explosion loads and that APM method can predict the behavior of progressive collapse in bridges [1].

In his master's thesis, Nielsen (2016) addressed different methods of calculating robustness which is an important indicator to determine is a structure is healthy against an initial local failure. In general, it was found that ductility and additional provisions against unpredicted vertical and horizontal loads increase human errors and that increase in the capacity of healthy structure makes it more robust [6].

Jinkoo Kim and Taewan Kim (2011) examined the resistant capacity of steel moment frames against progressive collapse. In this study, linear and nonlinear static and dynamic analysis methods are provided to compare according to the $2113 \mathrm{GSA}$ and $2115 \mathrm{DOD}$ regulations. After results of analysis are compared it was concluded that nonlinear dynamic analysis is an accurate tool to assess the potential of progressive collapse in building structures [10].

Jesse Karns and David Houghton (2015) evaluated potential of progressive collapse in steel frames with different connections. In this study, after nonlinear dynamic analysis of a 23-storey steel frame which had lost a critical column due to an unusual loading, the history of different eras and deformations obtained were applied to a finite element model (FEM) with full details on beam and column and a variety of beam-column connections. It became clear that the connection of side plate represent an appropriate behavior to withstand deformations created and deal with progressive collapse [11].

Jinkoo Kim and Dawoon An (2016) studied the effect of chain performance on the progressive collapse potential in steel moment frame buildings. Nonlinear dynamic and static analysis was performed in 3 and 6 storey models with and without brace using APM method proposed in 2113GSA regulation and then results were compared. When chain performance was included in nonlinear static analysis, the push-down curve obtained was placed above the curve without considering performance chain. Like spans and 
additional braces, the chain effects reduced lateral movements however changes made in number of storeys did not have a significant impact on chain performance [20].

Khalid Jalal and Tamer Alsavy (2011) investigated the impact of different rehabilitation strategies on reduction of progressive collapse in steel frames designed for gravity load using APM proposed by GSA and DOD. Response of three-dimensional nonlinear dynamic analyses for structures with different number and length of span in 10-storey steel frames were compared with the situation where different columns are eliminated. It was found that type of loading affects on potential of progressive collapse so all column removing scenarios with loading based on DOD resulted in the destruction of building but no such thing happened for GSA-based loading. It was also revealed that increase in beams strength is much more effective than increasing the stiffness [30].

Structural systems function differently in progressive collapse scenario. Study of different structural systems helps us investigate their potential in prevention of progressive collapse. The knee brace is one of the modern structural systems. Because of its knee member which yields against seismic load, this system increases energy dissipation of the structure. In fact, the knee element functions as a key that turns into a damper as soon as yielding which results in energy dissipation of the structure. This article aimed to examine behavior of moment framed structural system with knee brace at risk of progressive collapse under gravity and seismic loads. To better understand the behavior of this type of structural system, knee braced frames will be evaluated along with concentrically braced frames.

\section{MODELS}

In this study, the progressive collapse was evaluated focusing on steel structures with moment frame lateral load resisting with medium ductility along with knee brace. Furthermore, in order to better understand this type of brace in the scenario of progressive collapse, the knee brace was measured along with concentrically braced frames (CBFs). Structures were designed specifically for earthquake zones with soil of type III according to Iran's 2111 standard. Storeys were all in the same height of 3 meters. All joints and bearings are assumed to be rigid and roof system is composed of polystyrene piles with oneway performance and loads are distributed on beams in a plaid form. Gravity loading is done in accordance with the sixth issue of Iran's national regulation. Dead load cause by the ceiling and interior partitions for storeys and roof was respectively $500 \frac{K M}{M 2}$ and $600 \frac{K M}{M 2}$. In addition, the live load exerted on the surface was equal to $200 \frac{K M}{M 2}$ for storeys and $150 \frac{K M}{M 2}$ for roof. Sections used in beams and columns are respectively of IPE and $\mathrm{H}$ wide flange plate types. Beam-column materials were chosen of 73ST steel with minimum yield stress $\mathrm{Fy}=2400 \frac{K M}{C M 2}$ To calculate the weight of each storey during an earthquake, the whole dead load along with $21 \%$ the live load were included. In this study, 4,7 and 10 -storey building models were used that represent short, medium and relatively long structures. Structural plan in all floors has similarly three five-meter spans in both longitudinal and transverse directions which is demonstrated in Figure 1. In all models, the middle spans of side frames are equipped with knee braces. After initial design, the side frame of structure with knee brace was chosen as the one that is to be used in order to investigate the progressive collapse scenario.

Figure 1. Floor plan 


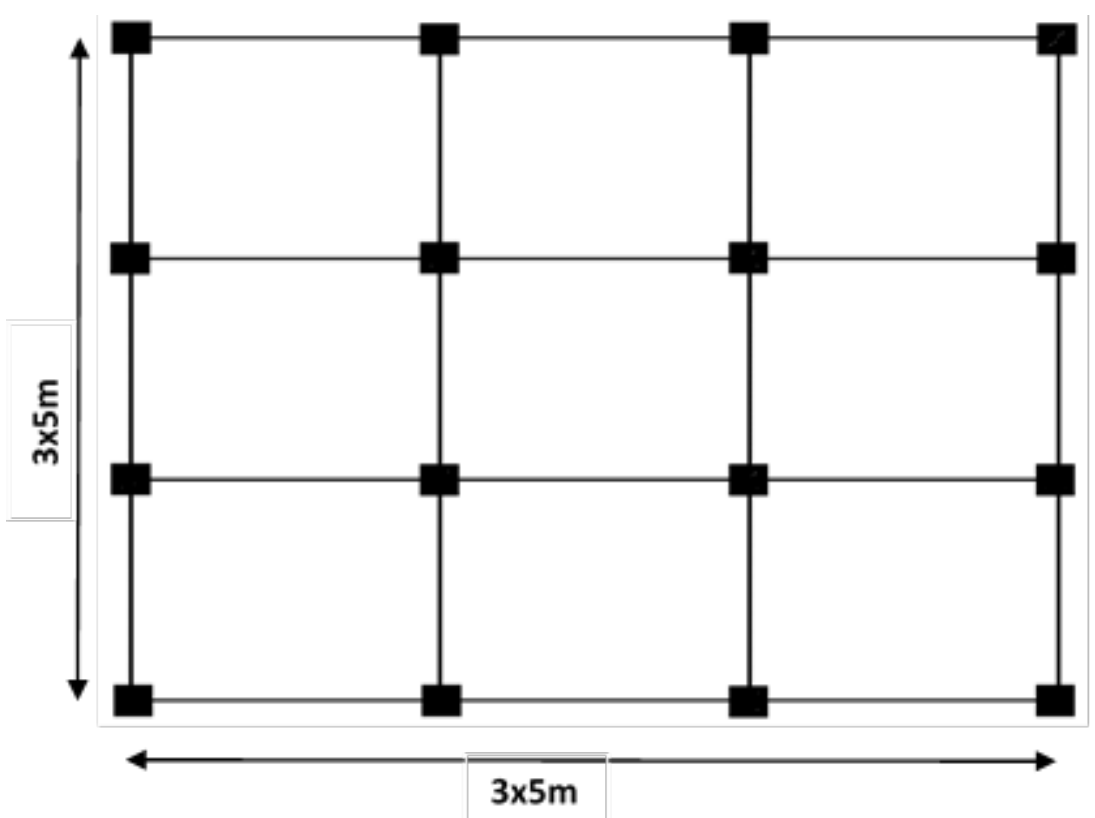

Specifications of sections of beams, columns, and knee elements are respectively represented in tables 1 , 2 and 3. Moreover, the modeled structured is shown in Figure 2:

Table 1. Specifications of columns sections in 4, 7 and 10-storey structural models

\begin{tabular}{|c|c|c|}
\hline \multirow{2}{*}{ Structural model } & Floors (storeys) & Columns sections \\
\hline \multirow{2}{*}{ 4-storey } & $1-2$ & $\mathrm{H} 091$ \\
\cline { 2 - 3 } & $3-4$ & $\mathrm{H} 021$ \\
\hline \multirow{3}{*}{ 7-storey } & $1-3$ & $\mathrm{H} 091$ \\
\cline { 2 - 3 } & $4-5$ & $\mathrm{H} 041$ \\
\cline { 2 - 3 } & $6-7$ & $\mathrm{H} 021$ \\
\hline \multirow{3}{*}{10 -storey } & $1-4$ & $\mathrm{H} 241$ \\
\cline { 2 - 3 } & $4-8$ & $\mathrm{H} 011$ \\
\hline
\end{tabular}

Table 2. Specifications of beams sections in 4, 7 and 10-storey structural models

\begin{tabular}{|c|c|c|}
\hline Structural model & Floors (storeys) & Beams sections \\
\hline 4 -storey & $1-4$ & IPE221 \\
\hline 7 -storey & $1-4$ & IPE291 \\
\hline
\end{tabular}


The Turkish Online Journal of Design, Art and Communication - TOJDAC August 2016 Special Edition

\begin{tabular}{|l|c|c|}
\hline & $5-7$ & IPE221 \\
\hline \multirow{2}{*}{10 -storey } & $1-5$ & IPE291 \\
\cline { 2 - 3 } & $5-10$ & IPE221 \\
\cline { 2 - 3 }
\end{tabular}

Table 3. Specs of knee elements sections

\begin{tabular}{|c|c|c|}
\hline Structural model & Floors (storeys) & Knee element sections \\
\hline \multirow[t]{2}{*}{ 4-storey } & 1 & IPE011 \\
\hline & $3-4$ & IPE021 \\
\hline \multirow{3}{*}{ 7-storey } & $1-2$ & IPE221 \\
\hline & $3-4$ & IPE011 \\
\hline & $4-7$ & IPE021 \\
\hline \multirow{3}{*}{ 10-storey } & $1-4$ & IPE241 \\
\hline & $4-8$ & IPE011 \\
\hline & $8-10$ & IPE021 \\
\hline
\end{tabular}

Figure 2. Structural models of a structure with knee brace

A) 10-storey, B) 7-storey, C) 4-storey 


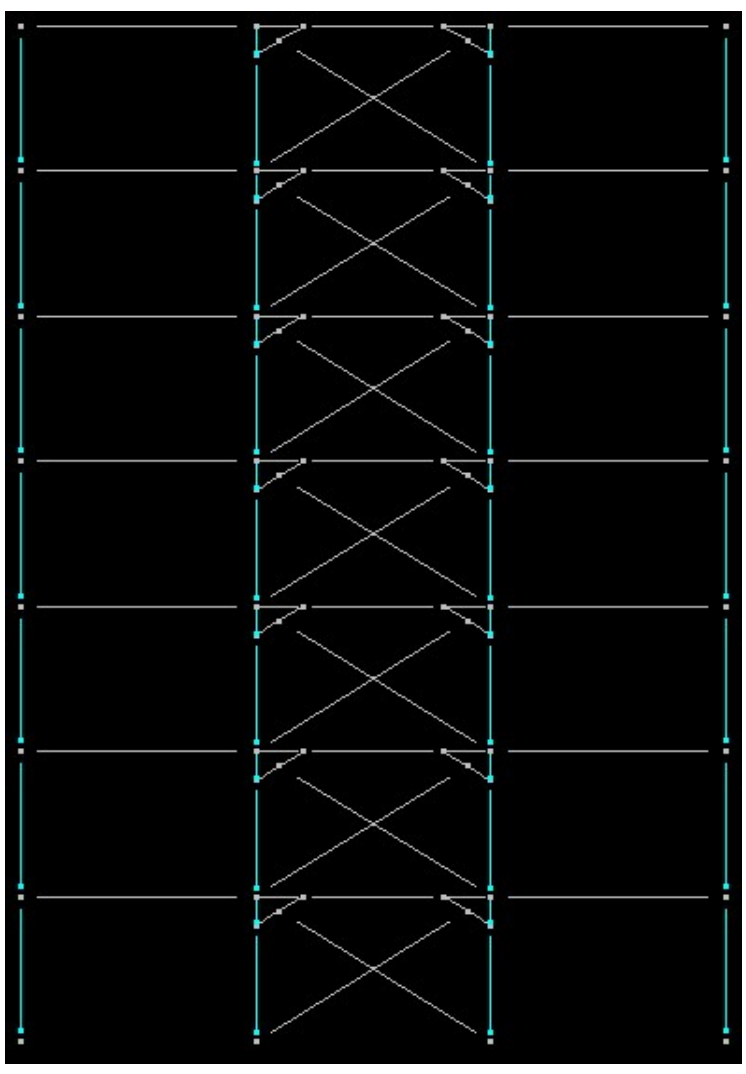

(B)

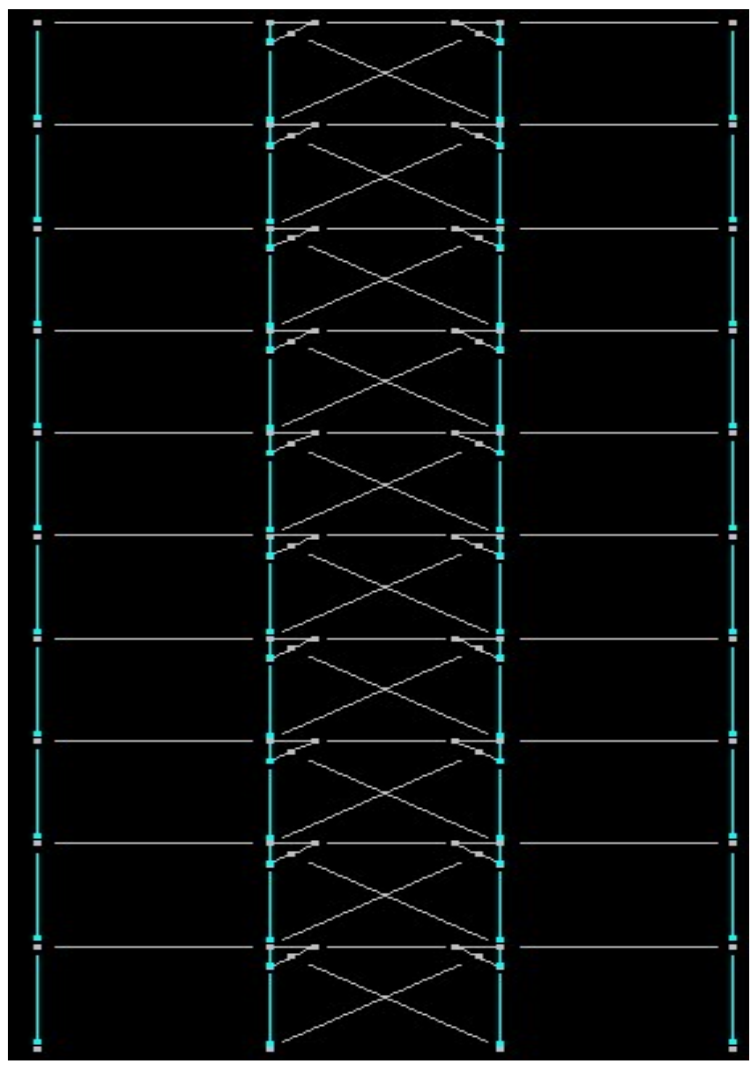

(A) 


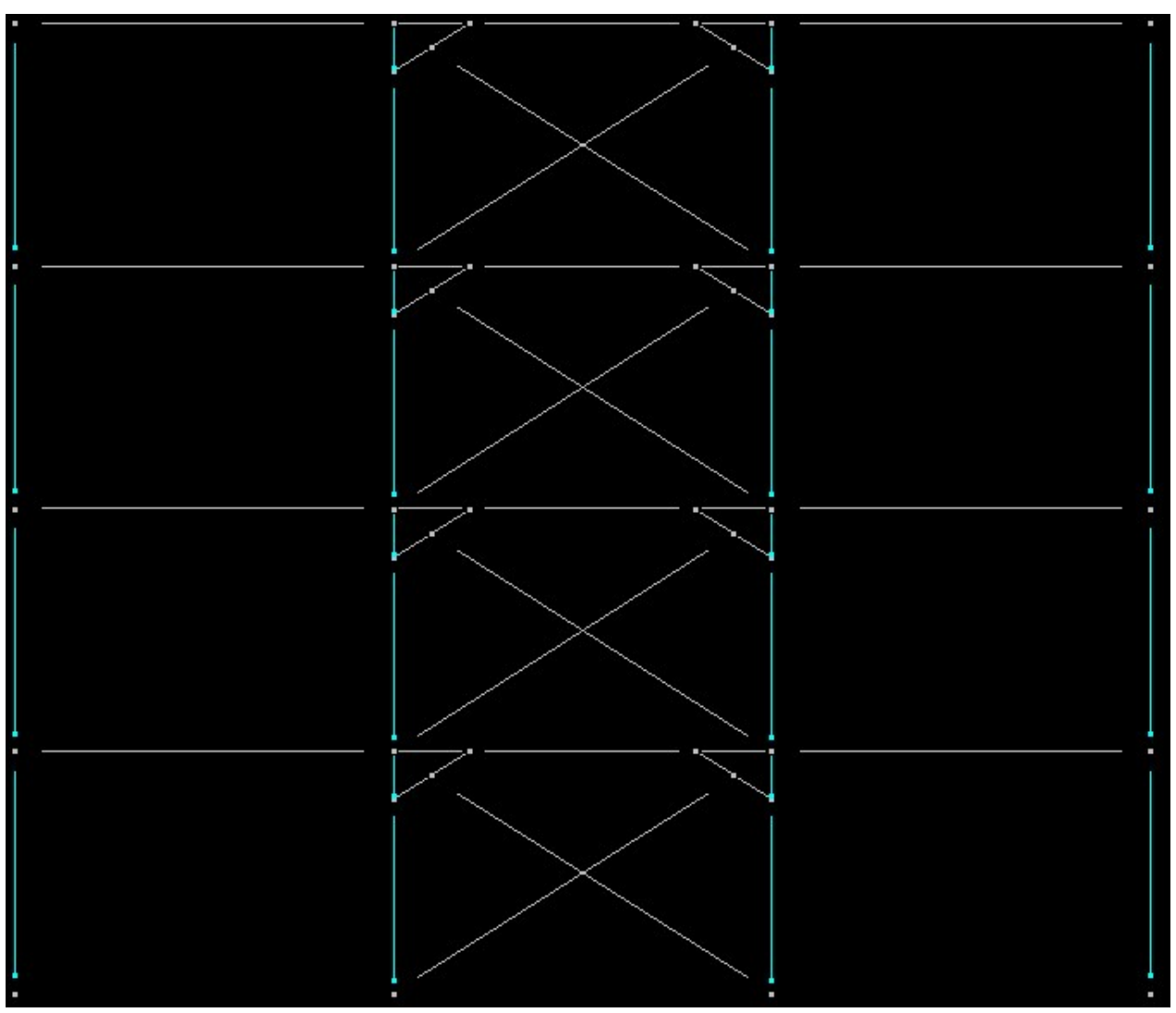

(C)

\section{ANALYSIS METHOD}

To assess the potential of progressive collapse, the alternate load path method was used. According to this method, one of the structural elements that is locally failed is eliminated and then the structure will be analyzed without having the injured member. After analysis, it is determined what impact the removal of the element has had on how loads are redistributed. In this study, the progressive collapse of structure is considered based on gravity and seismic loads. Techniques used to evaluate the potential of progressive collapse under gravity load and seismic load were respectively push down nonlinear static method and nonlinear dynamic. According to GSA regulations, after injured element is removed in nonlinear push down static analysis, gravity load on damaged span is multiplied by 2 (Figure 3) and then structure under gravity or lateral load is analyzed. So to measure the potential of progressive collapse on damaged span, the load combination (DL+1.25LL)2 and in other spans the DL+1.25LL combination are used. To assess the potential of progressive collapse under seismic load, the El Centro, Northridge and Loma earthquakes were used. All earthquakes were scaled to the maximum acceleration of g1.35. The specifications of these earthquakes are represented in Table 4.

Table 4. Earthquakes features

\begin{tabular}{|c|c|c|c|c|}
\hline No & Earthquake name & $\begin{array}{c}\text { Distance from } \\
\text { fault }(\mathrm{km})\end{array}$ & Station name & $\begin{array}{c}\text { PGA (g) } \\
\text { In x direction }\end{array}$ \\
\hline 1 & EL Centro (Imperial Valley) & 43.6 & Delta & 0.238 \\
\hline
\end{tabular}




\begin{tabular}{|c|c|c|c|c|}
\hline 2 & Loma Prieta & 16.1 & Gilroy Array & 0.417 \\
\hline 3 & Northridge & 17 & Newhall & 0.32 \\
\hline
\end{tabular}

Figure 3. Vertical load imposed in nonlinear push down static analysis in accordance with 2113GSA Regulation

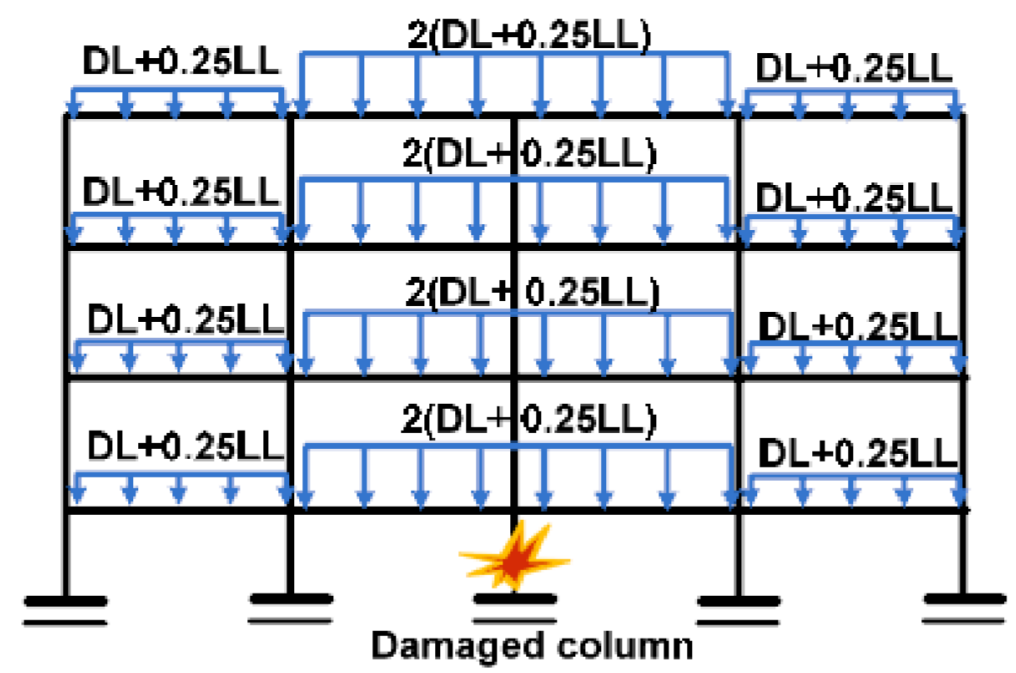

To create local damage in the structures, the alternate load path method was used according to the GSA Regulation. According to this regulation, local damages caused by column removal should be imposed in a way that won't injure the connections of the beam above that area so loads will be redistributed properly. In this paper, different failure modes were applied including eliminating the column alone and removal of both column and brace together. Different local failure modes here are shown in Table 5. An example of structures with local failure is represented in Figure 4.

Table 5. Different modes of local failure

\begin{tabular}{|c|c|c|c|}
\hline Representing phrase & Removing storey & Removing mode & Structural model \\
\hline Damaged 1 & \multirow{6}{*}{ First } & Corner column & \multirow[t]{2}{*}{ 4-storey structure } \\
\hline Damaged 2 & & Middle column + brace & \\
\hline Damaged 1 & & Corner column & \multirow[t]{2}{*}{ 7-storey } \\
\hline Damaged 2 & & Middle column + brace & \\
\hline Damaged 1 & & Corner column & \multirow[t]{2}{*}{ 10-storey } \\
\hline Damaged 2 & & Middle column + brace & \\
\hline
\end{tabular}


Figure 4. An example of a local failure in the 10-storey structure

A) damaged 1 and B) damaged 2
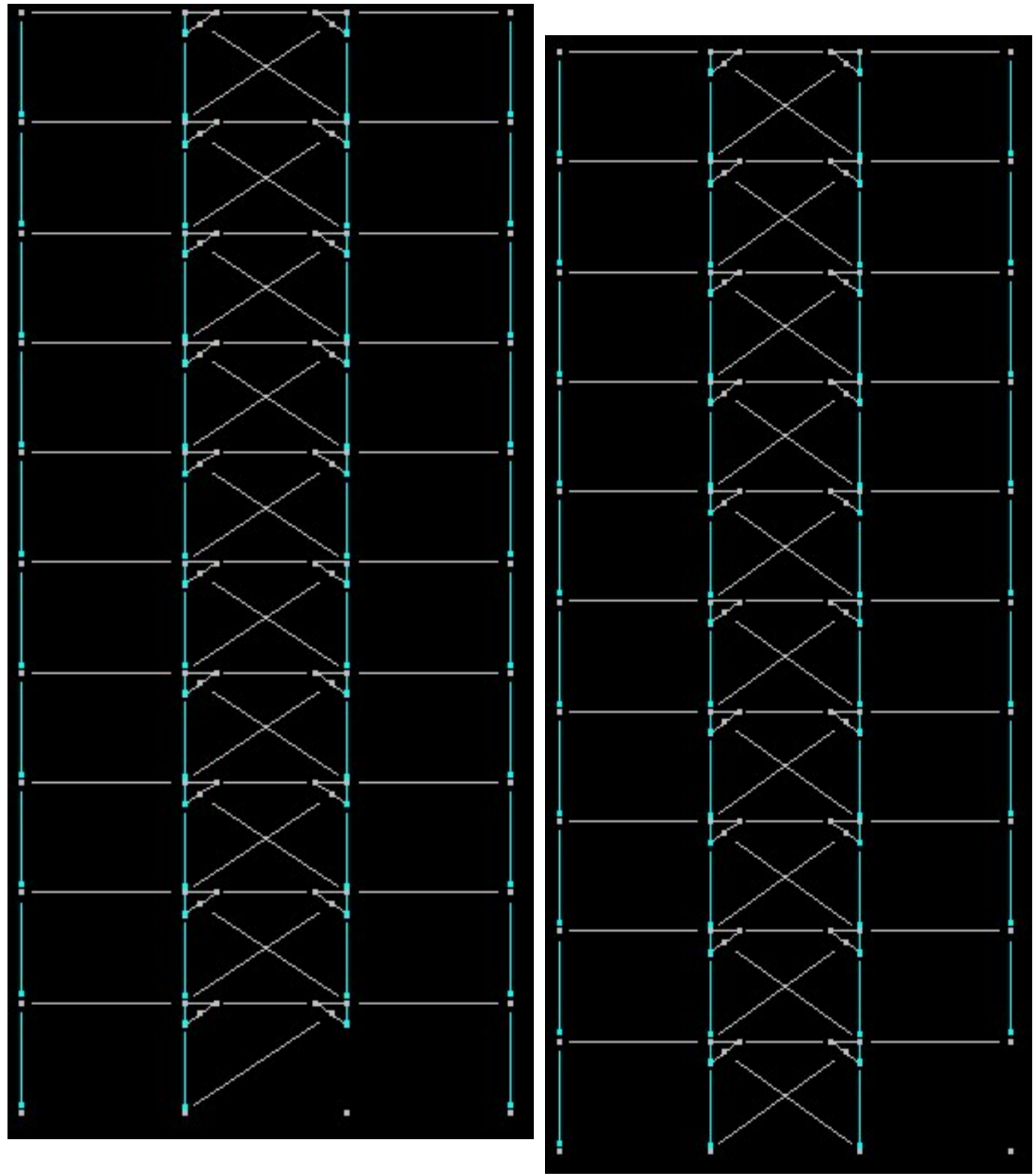

(B)

(A) 


\section{RESULTS}

Results of push down analysis

As explained before, push down static analysis was used to examine the potential of progressive collapse. Based on this analysis, gravity load is applied to structure step by step and the vertical displacement of the spot above the element eliminated is read each time. Finally, vertical displacement value of the spot above removed element is drawn based on gravity load factor on each step. The curve drawn is called structure push down curve. The higher the load factor calculated in a certain displacement is, the more resistant the structure will be against failure under gravity load. In other words, the higher the load factors is, the higher gravity load the structure needs to reach the displacement desired. Push down curve of 4, 7 and 10storey structures for damaged-1 state is illustrated in Figure 5 and for damaged-2 state in Figure 9.

Figure 5. Push down curve of structures in damaged-1 state: A) 4-storey, B)7-storey, C) 10-storey

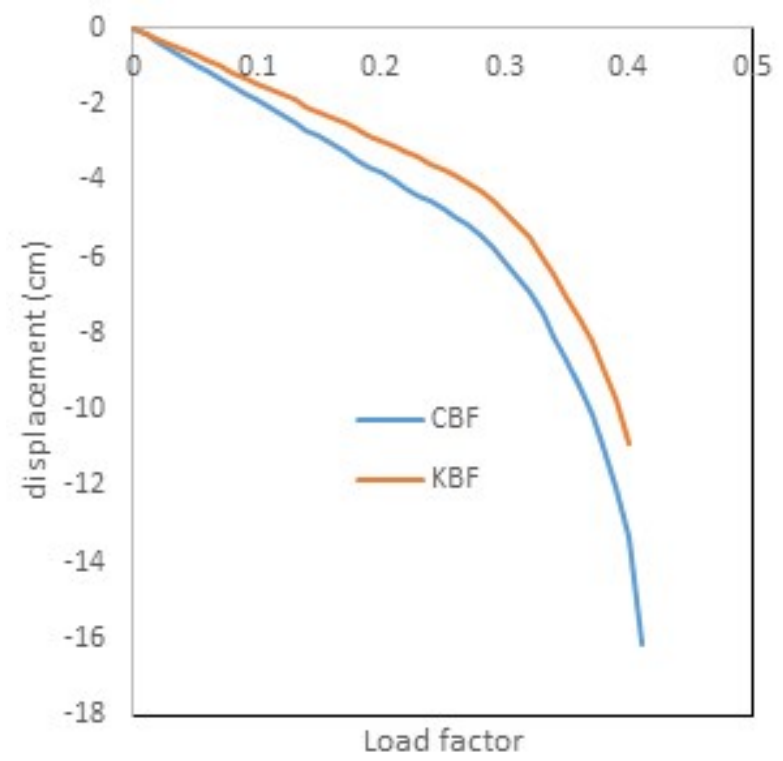

(B)

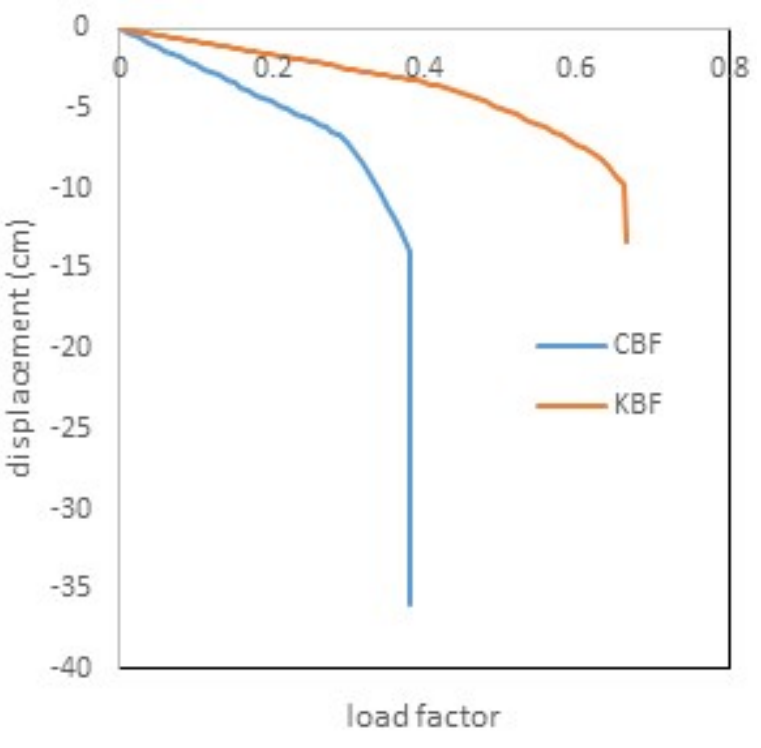

(A) 


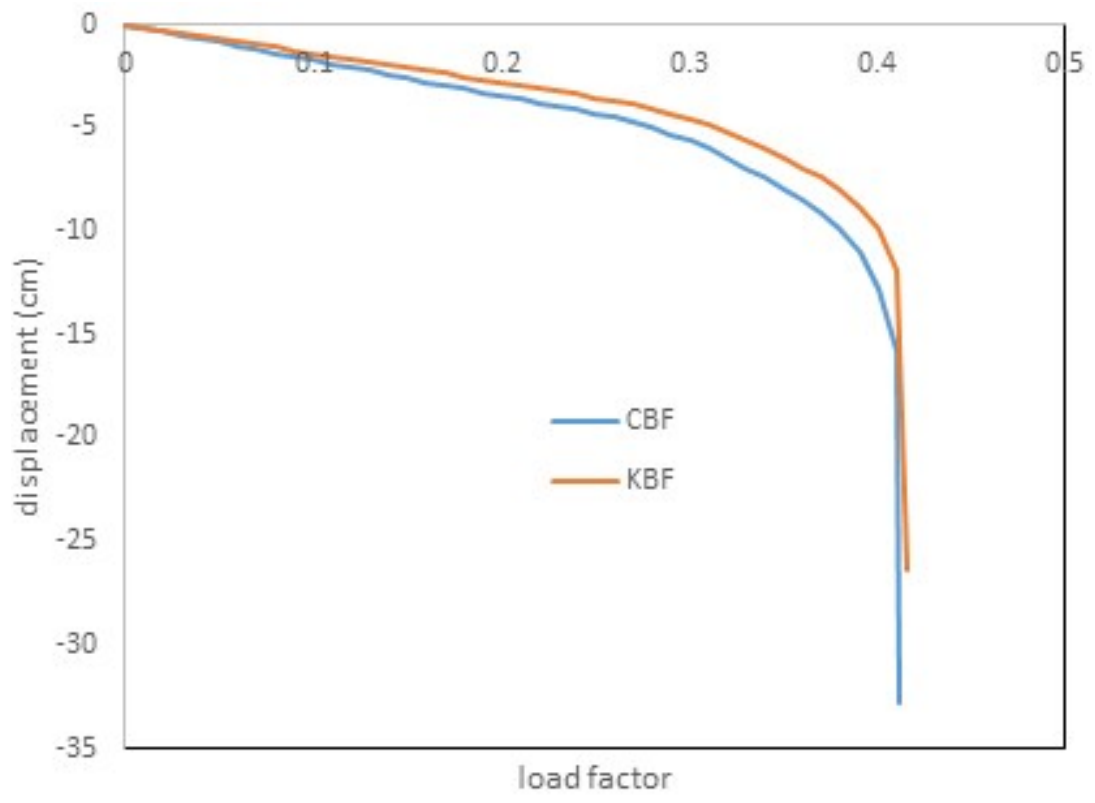

(C)

Push down curves of the structures for damaged-1 mode in two concentrically braced frame (CBF) and knee braced frame (KBF) are presented in Figure 5. Push down curve reflects structures capacity under gravity load. According to this figure, knee brace has shown a better performance in all structures. In fact, structures with knee brace under gravity load are more resistant than structures with concentrically braced frames. The knee member allows such structures to redistribute the loads more properly besides it lowers the displacement of structure under gravity load. The same process applies to the damaged-2 mode as well.

Figure 9. Push down curve of structures in damaged-2 state: A) 4-storey, B)7-storey, C) 10-storey
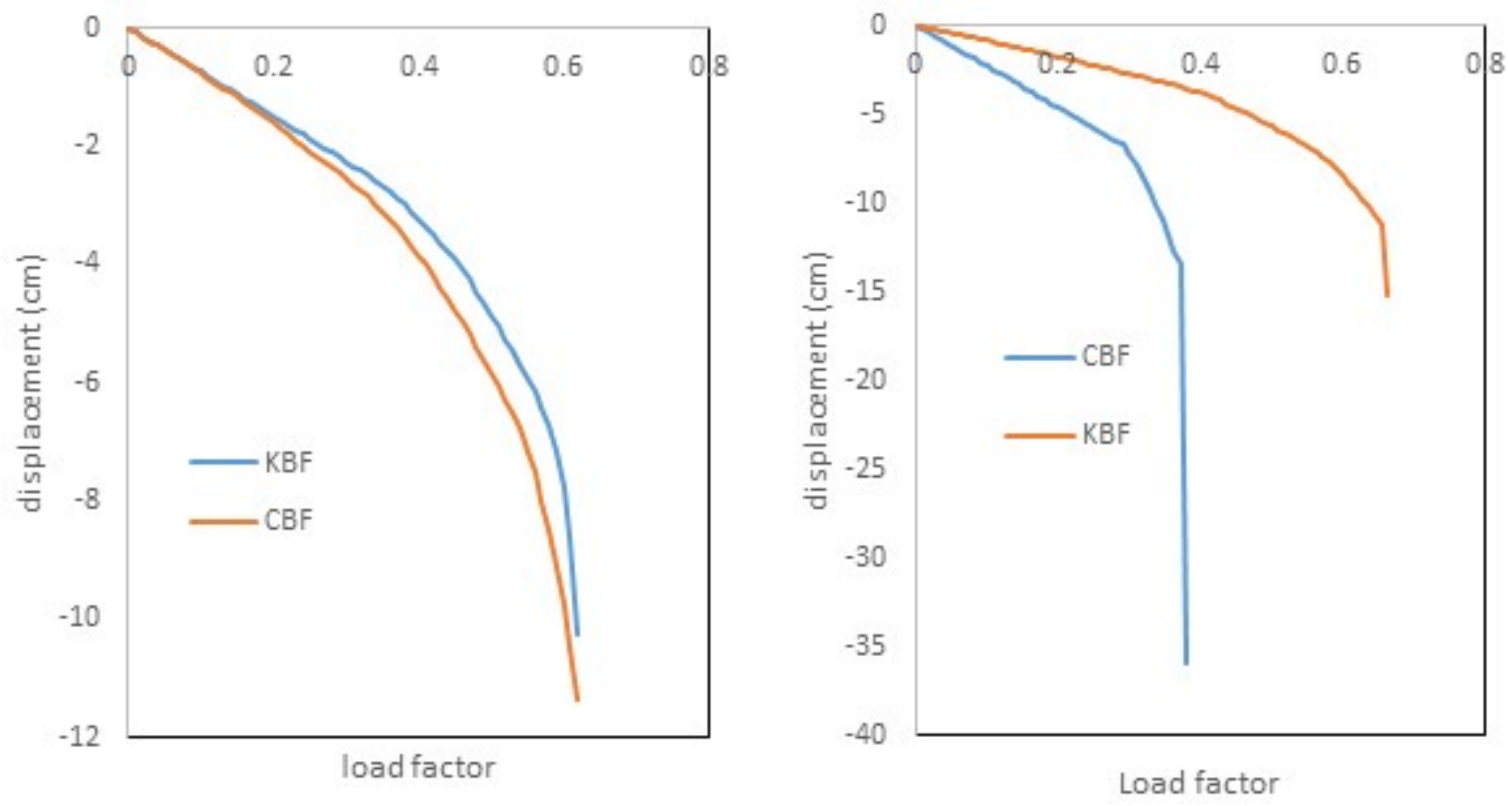
(B)

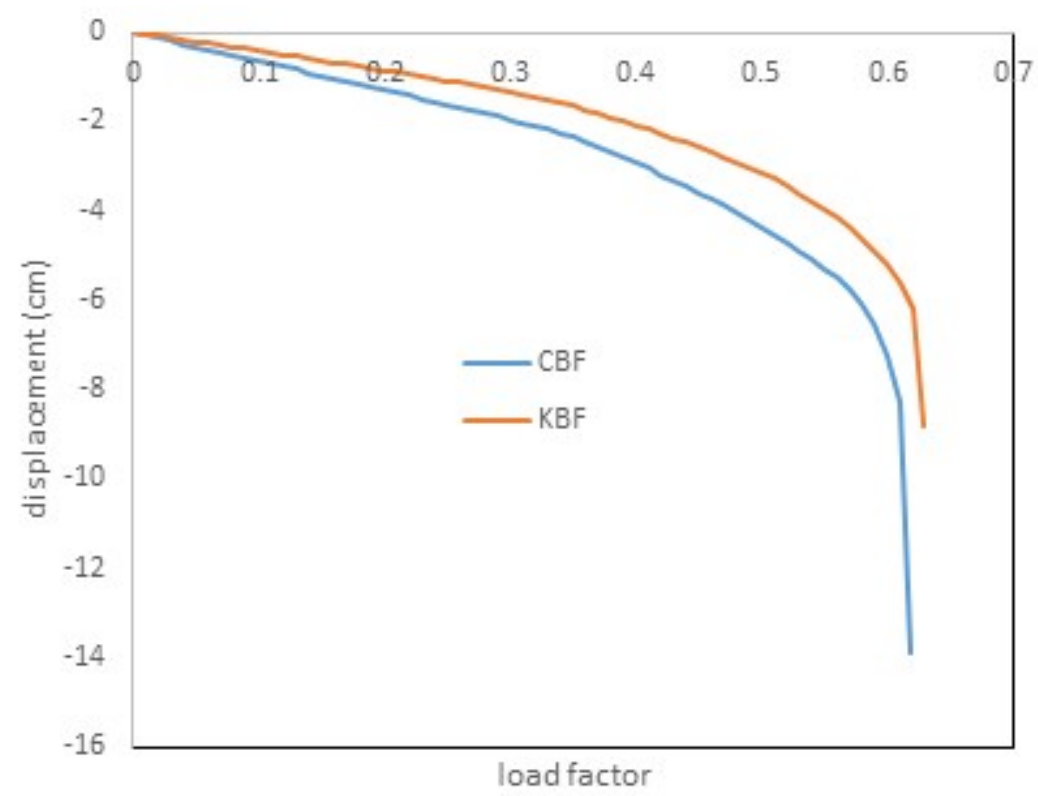

(C)

In damaged-2 state like damaged-1 state, structure with knee brace has a greater capacity to withstand gravity load. A comparison of different failure modes and structural models indicates that knee elements increases the structure resistance against gravity load. As a matter of fact, when column is eliminated a traction force flow is created in the structure. Then the knee element strengthens structure's chain performance resulting in increased resistance and load redistribution.

\section{Results of seismic load in the progressive collapse scenario}

To evaluate the structures performance against seismic progressive collapse and determine the behavior of structures introduced under local failure, nonlinear dynamic analysis was used. In this regard, first the local failure was created in structures according to Table 5. Afterwards, damaged structures were exposed to seismic load caused by earthquakes mentioned in Table 4 . In addition, the maximum possible drift value in the structure set was 0.1 so analysis will stop upon reaching the drift figure and the overall damage imposed will be calculated. The results of the analysis based on roof displacement parameters, maximum drift of storeys and the base shear were assessed. Figure 7 displays the results of seismic progressive collapse in four-storey structure with knee brace.

Figure 7. Roof displacement curve of structures with knee brace under earthquakes A) Loma, B) Northridge, C) EL Centro 
The Turkish Online Journal of Design, Art and Communication - TOJDAC August 2016 Special Edition

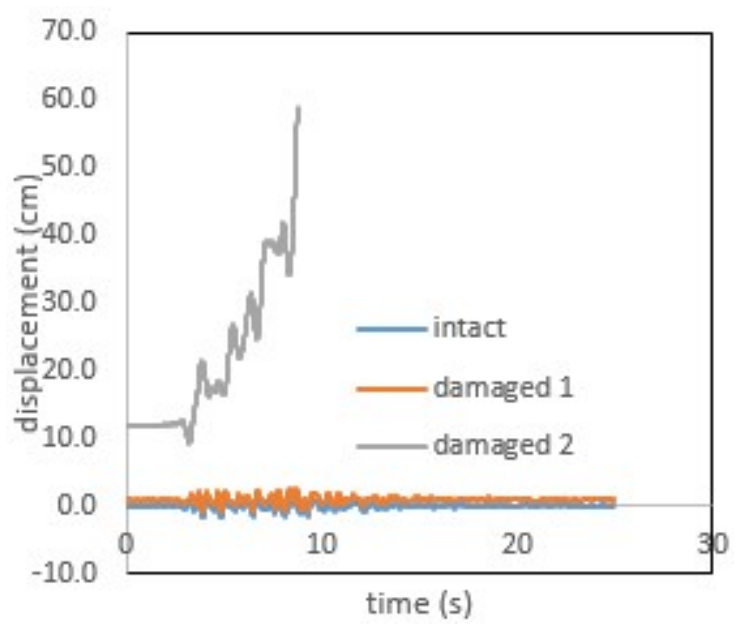

(B)

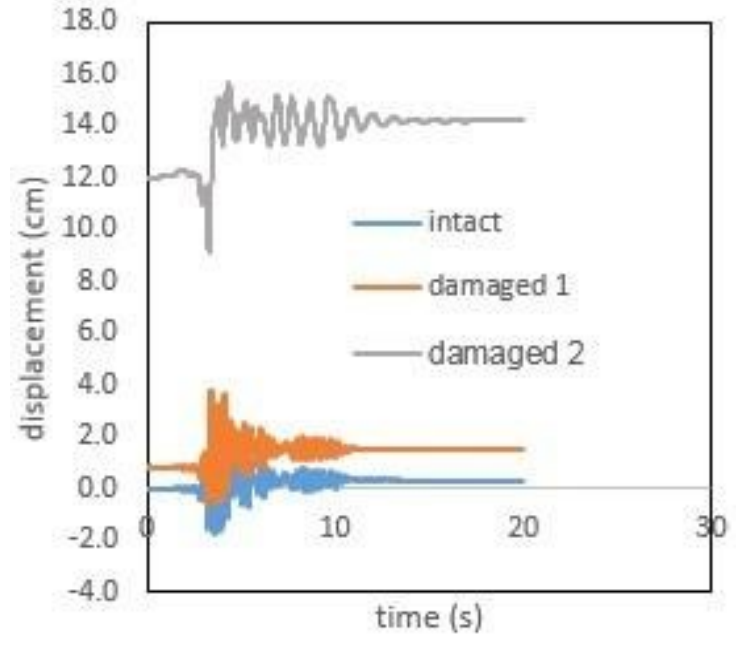

(A)

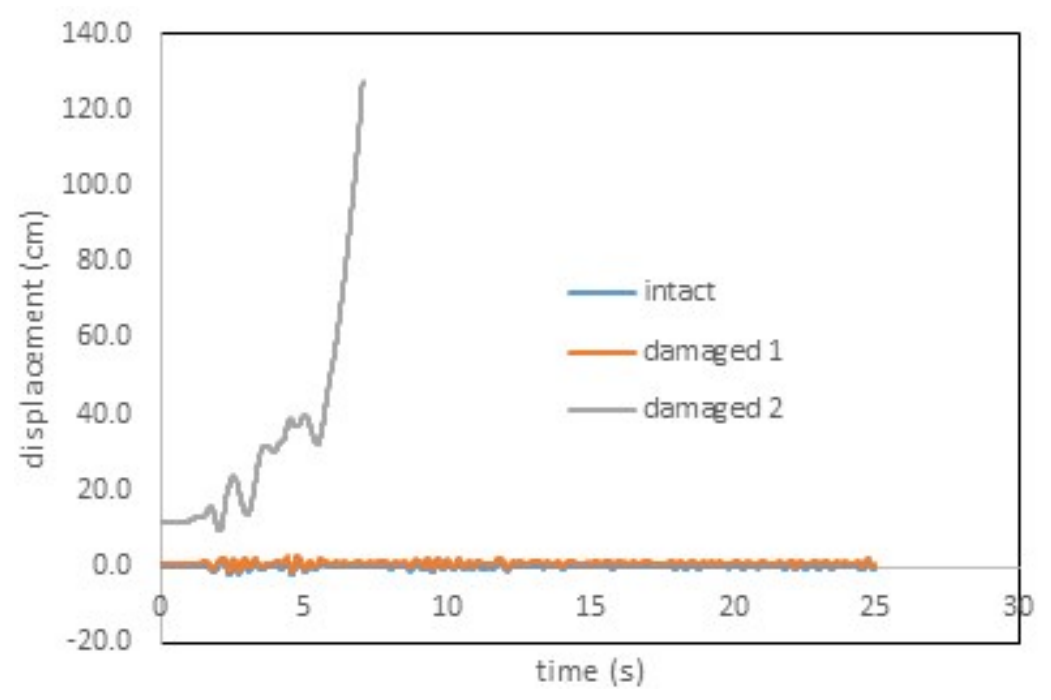

(C)

Based on this figure, roof displacement of damaged structures in all three earthquakes was higher than healthy structure. Column removal however did not affect much roof displacement of structures with damage-1 failure. In fact, elimination of corner column in structures with knee brace under seismic load had less impact on structures performance than when damage was imposed on the center of span. Besides, structures were unstable during two earthquakes Northridge and El Centro and damaged-2 state. The point is failure of both column and brace in the structure with knee brace causes its progressive collapse and overall damage. Figure 1 represents roof displacement curve in seven and ten-storey structures with knee brace.

Figure 1. Roof displacement curve of structures with knee brace under earthquakes A) 7-storey structure, Loma; B) 7-storey structure, Northridge; C) 7-storey structure, El Centro; D) 10-storey structure, Loma;

E) 10-storey structure, Northridge; F) 10-storey, El Centro 
The Turkish Online Journal of Design, Art and Communication - TOJDAC August 2016 Special Edition

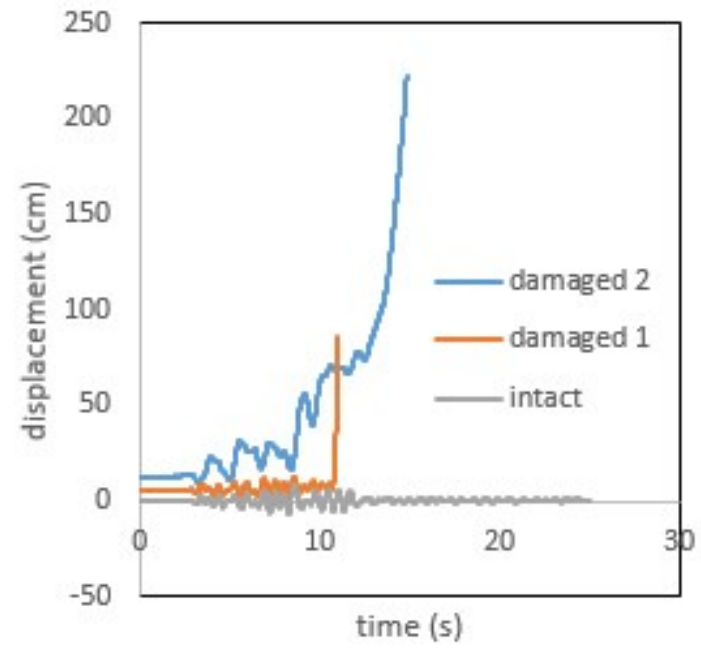

(B)

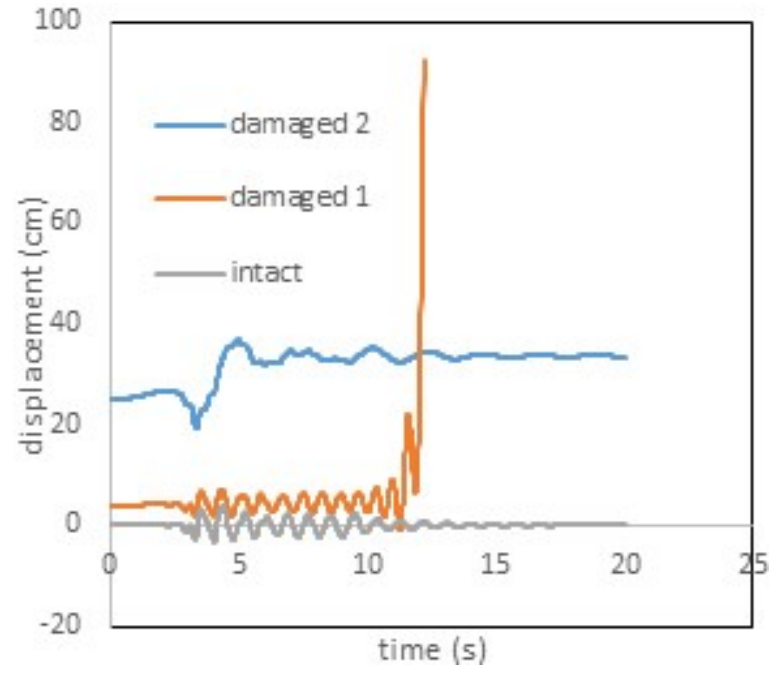

(D)

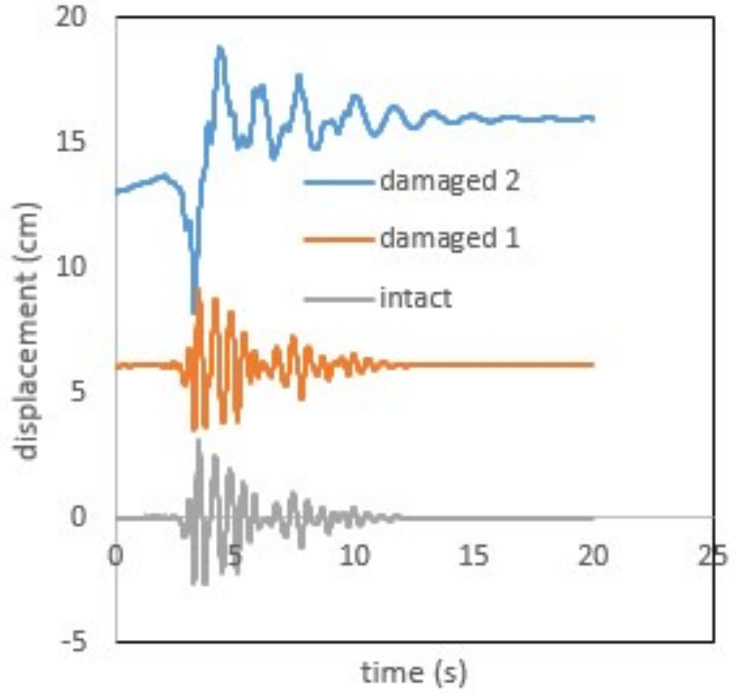

(A)

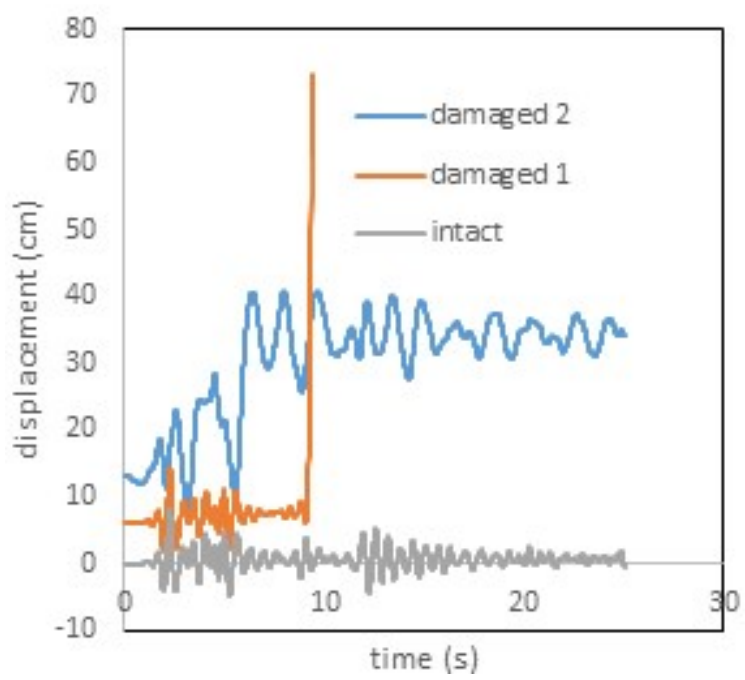

(C) 


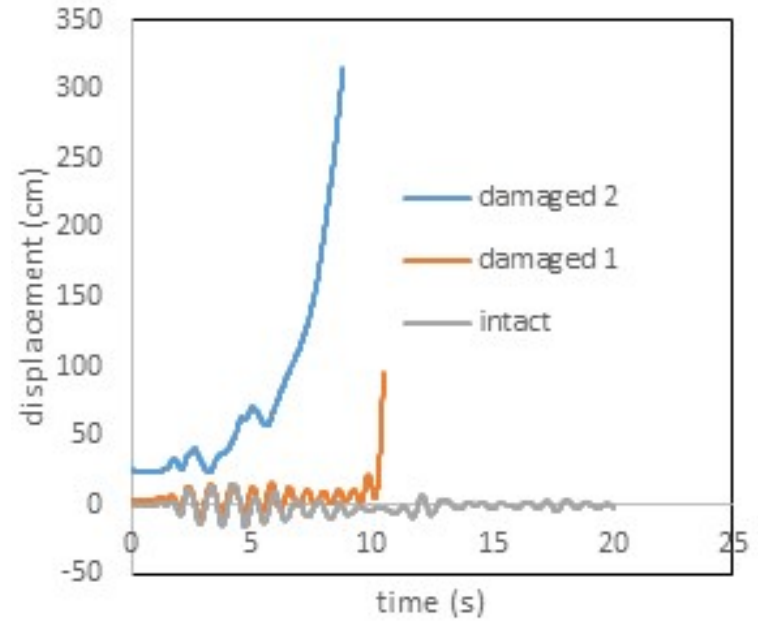

(F)

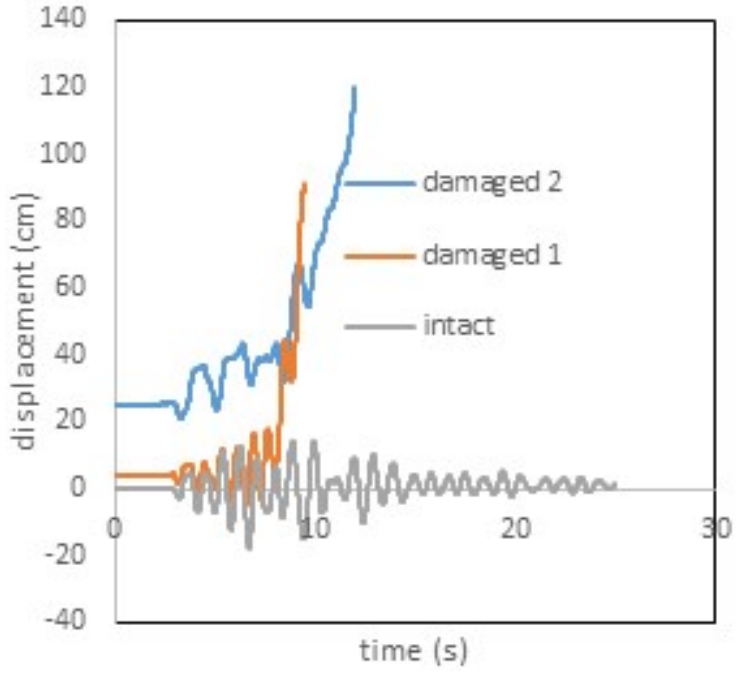

(E)

As can be observed, the sensitivity of 7 and 10-storey structures to local damage is increased in a way that local failure in 10-storey structure has sharply increased roof displacement during various earthquakes and led to instability of damaged structure except for one case. In CBF structures, local failure in all models during earthquakes has increased roof displacement and made the structure instable like knee brace structures.

An example of roof displacement in 10-storey structure with concentrically braced frame under El Centro Earthquake is shown in Figure 6.

Figure 6. Roof displacement of 10-storey structure with concentrically braced frame under El Centro Earthquake

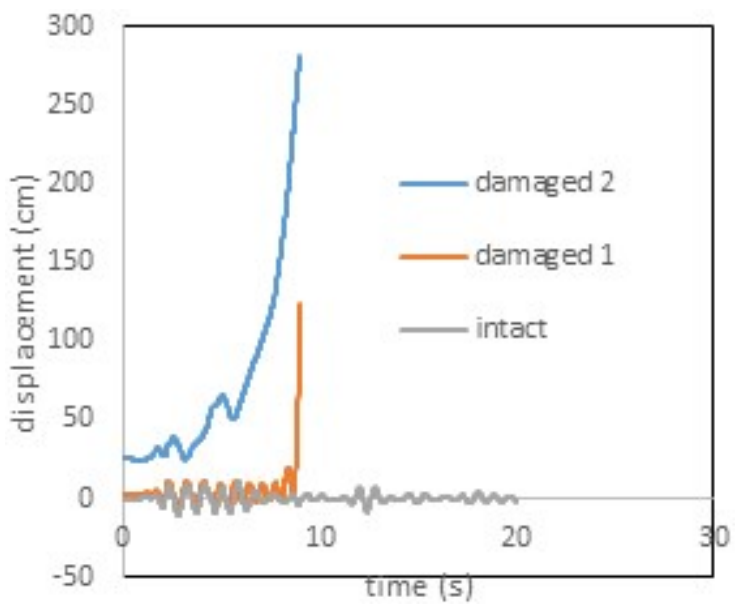

The base shear curve of structures under earthquakes mentioned is addressed below. The base shear curve of healthy and damaged 4-storey structures with knee brace is represented in Figure 10. 
Figure 10. The base shear curve of 4-storey structures with knee brace A) 4-storey structure, Loma; B) 4storey structure, Northridge; C) 4-storey structure, El Centro

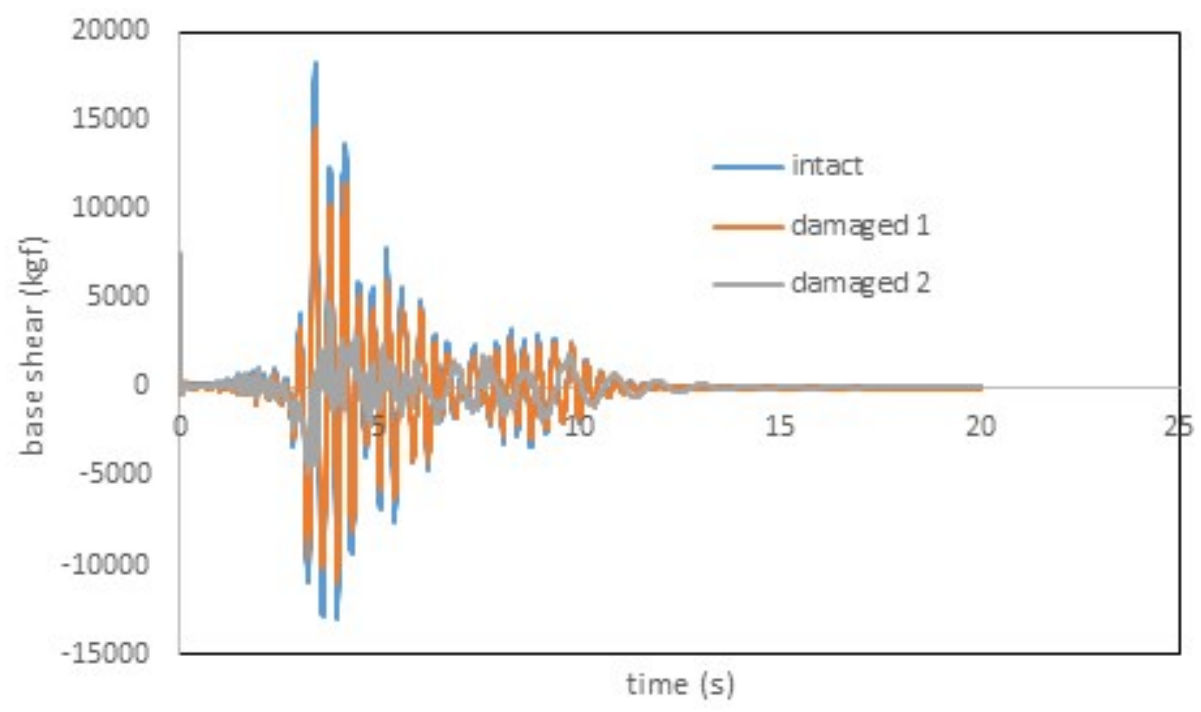

(A)

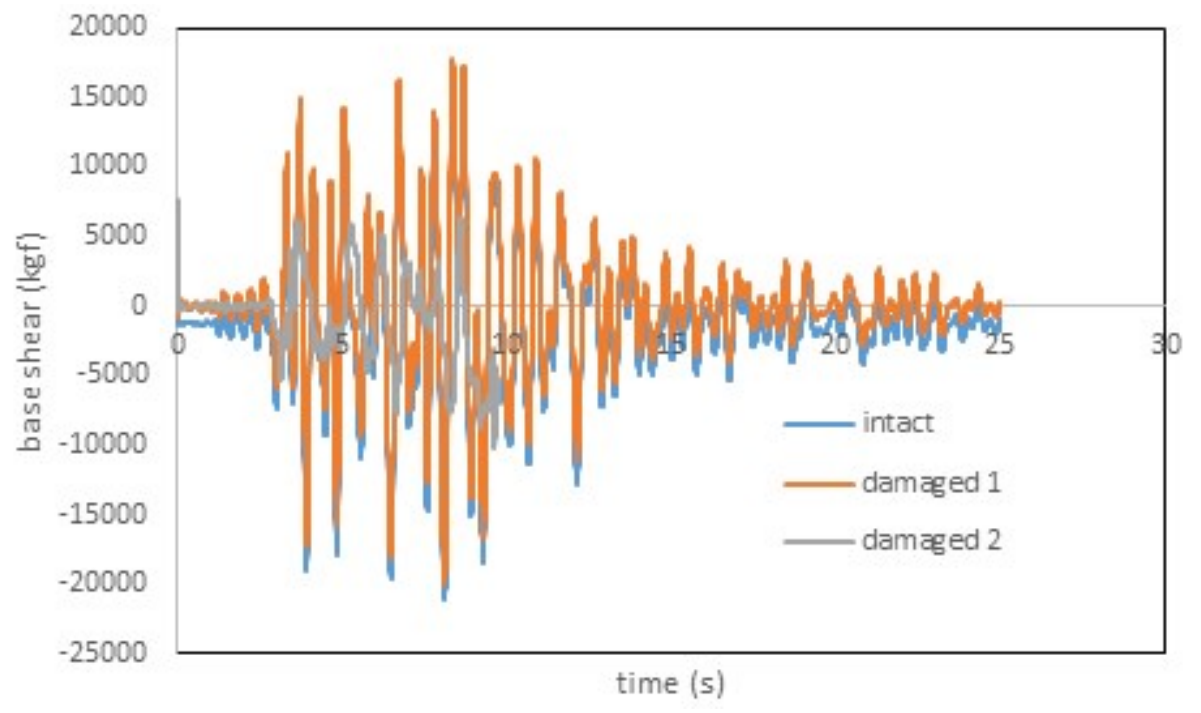

(B) 


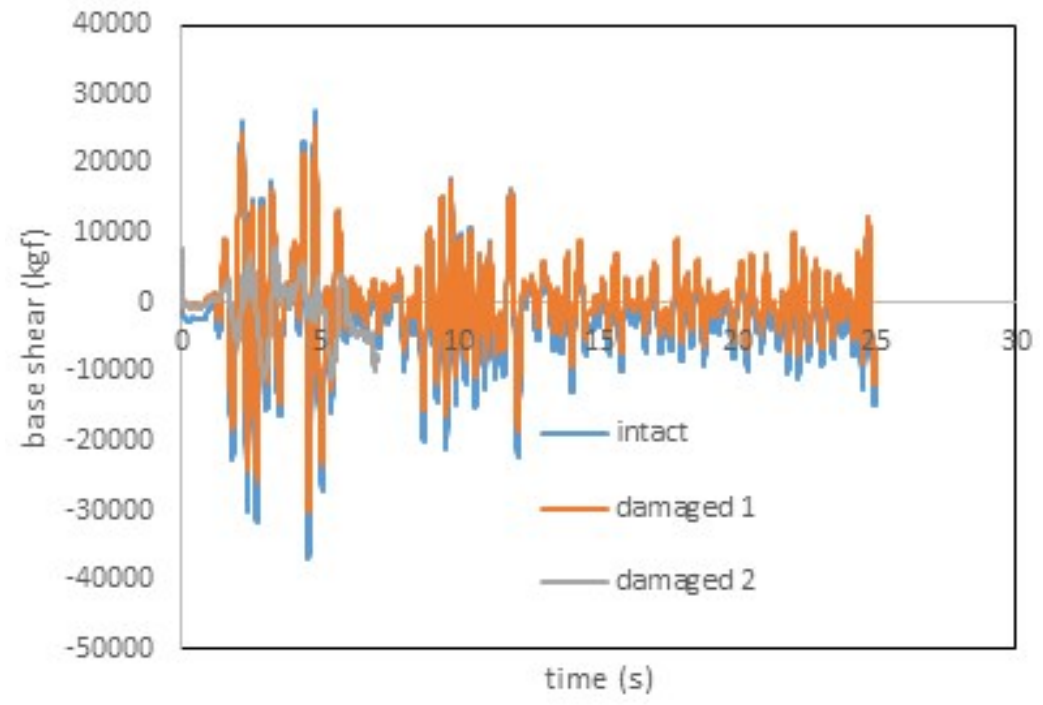

(C)

The results show that base shear curve of damaged structures is less than of that in healthy structures. Also, in all structures, the maximum base shear of healthy structure is less than damaged ones suggesting that shear capacity of damaged structures is less than healthy structure. These curves reflects the point that capacity reduction of structures with local damaged-2 failure was higher than structures with damaged-2 failure. Similarly in all 4, 7 and 10-storey models with damaged-2 state, the time history curve of base shear at time zero shows that the structure has the original shear. This specifies that after removal of column and load redistribution and rebalance, the structure is subject to residual base shear which affects structures behavior under dynamic load. The same process is going on in structures with CBF. The base shear curve of structures with CBF is presented in Figure 11. It is shown that removing the column element reduces structures base shear which is more noticeable in damaged-2 state.

Figure 11. Base shear curve of 4-storey structure with concentrically braced frame under earthquakes A) Loma, B) Northridge, C) El Centro

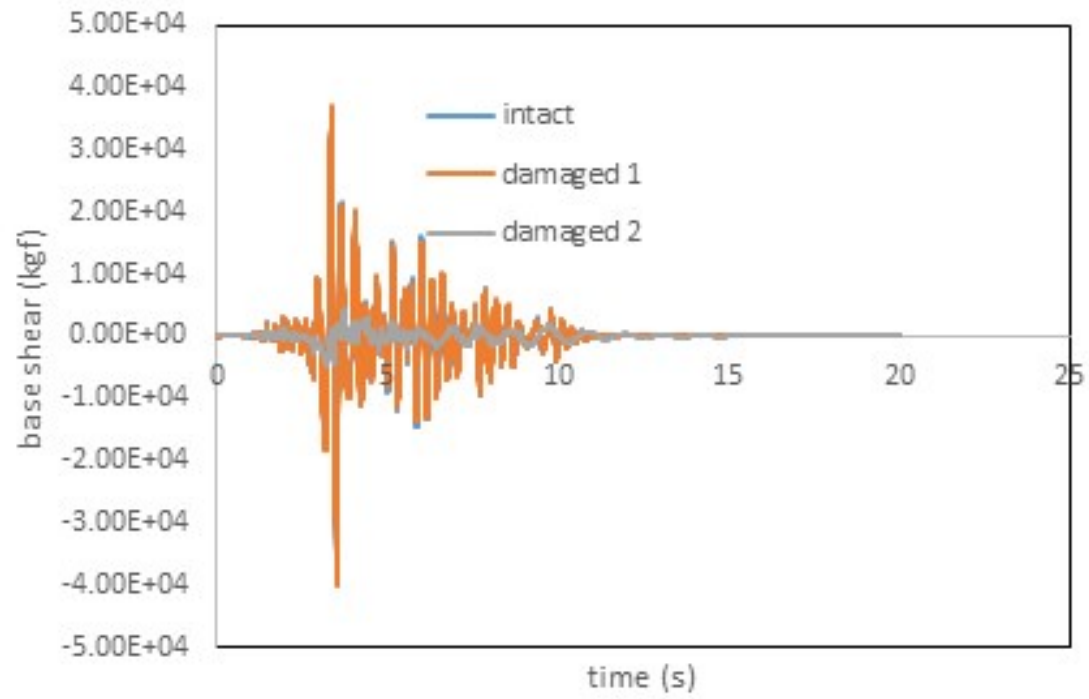




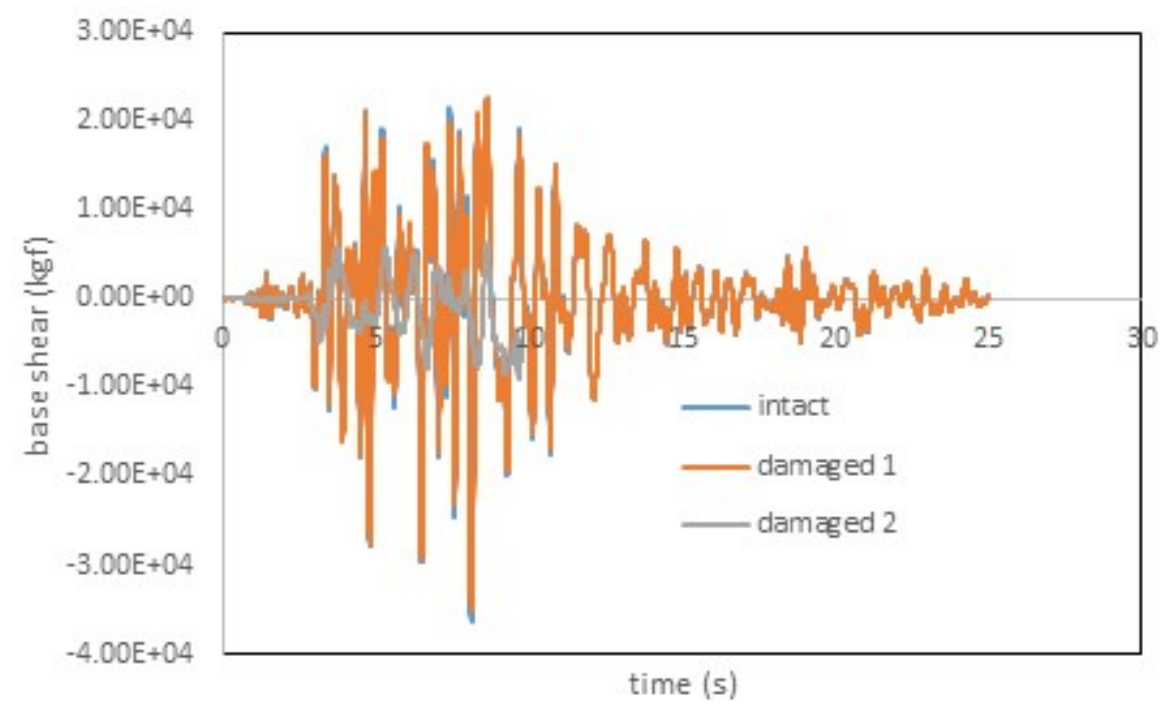

(B)

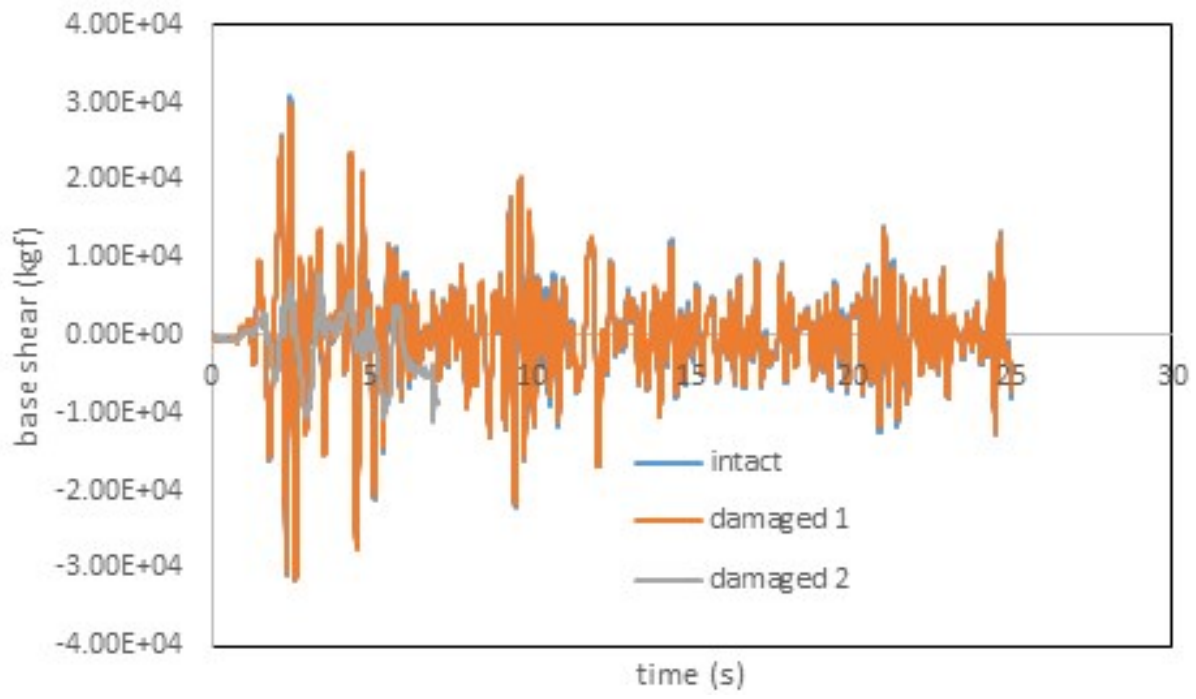

(C)

In the following part, maximum drift curve of structure in different floors is demonstrated. Figure 12 illustrates the maximum drift of floors in 4-storey structures with $\mathrm{CBF}$ and $\mathrm{KBF}$. According to this figure, storey drift of different structures has increased under various failures. Drift specifies what storeys are damaged the most and which storeys are affected by local failure more than the others. Based on Figure 12-A), drift of storeys in structures with CBF under Northridge Earthquake has reached the brink of destruction on 2nd, 3rd and 4th floors which stipulates that local failure on the first floor of this structural model had the greatest impact on the structural failure on its upper floors. Also, under this earthquake, the knee brace structure has a better performance than the structure with concentrically braced frame. 
Figure 12. Floors drift curve of 4-storey structure under earthquakes A) Northridge, B) Loma, C) El Centro

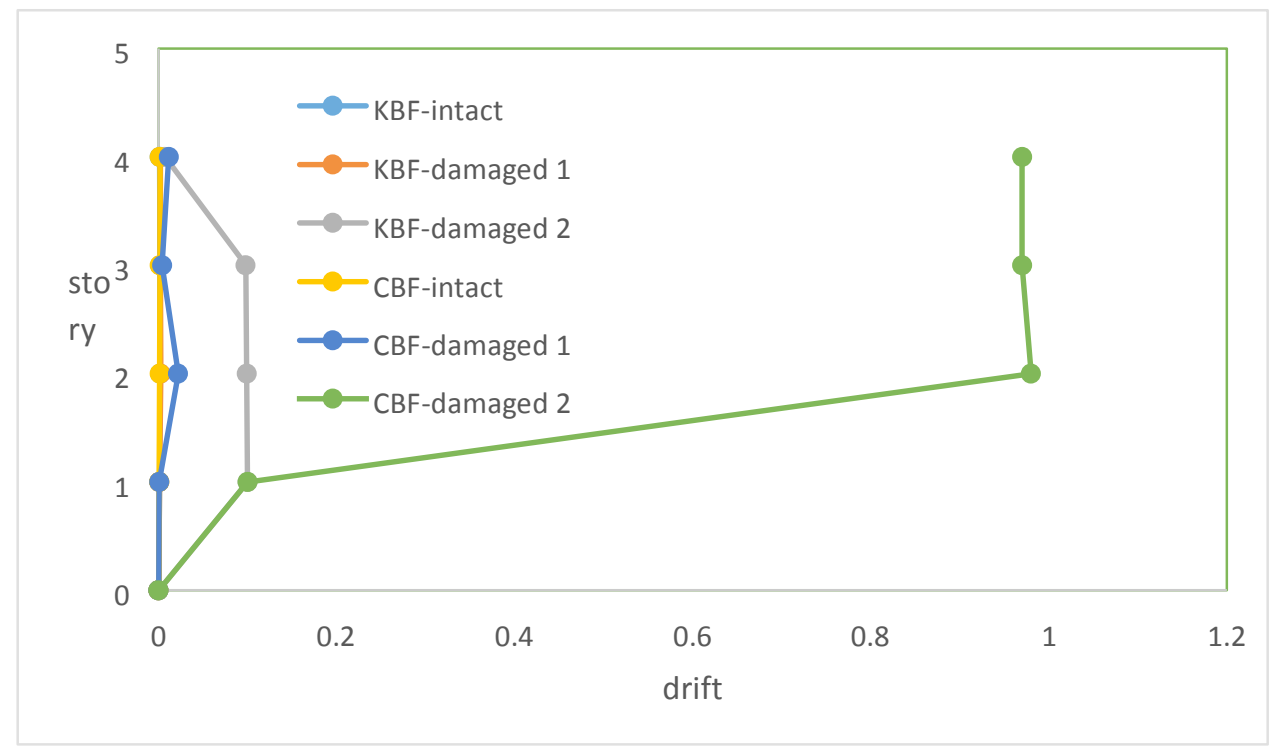

(A)

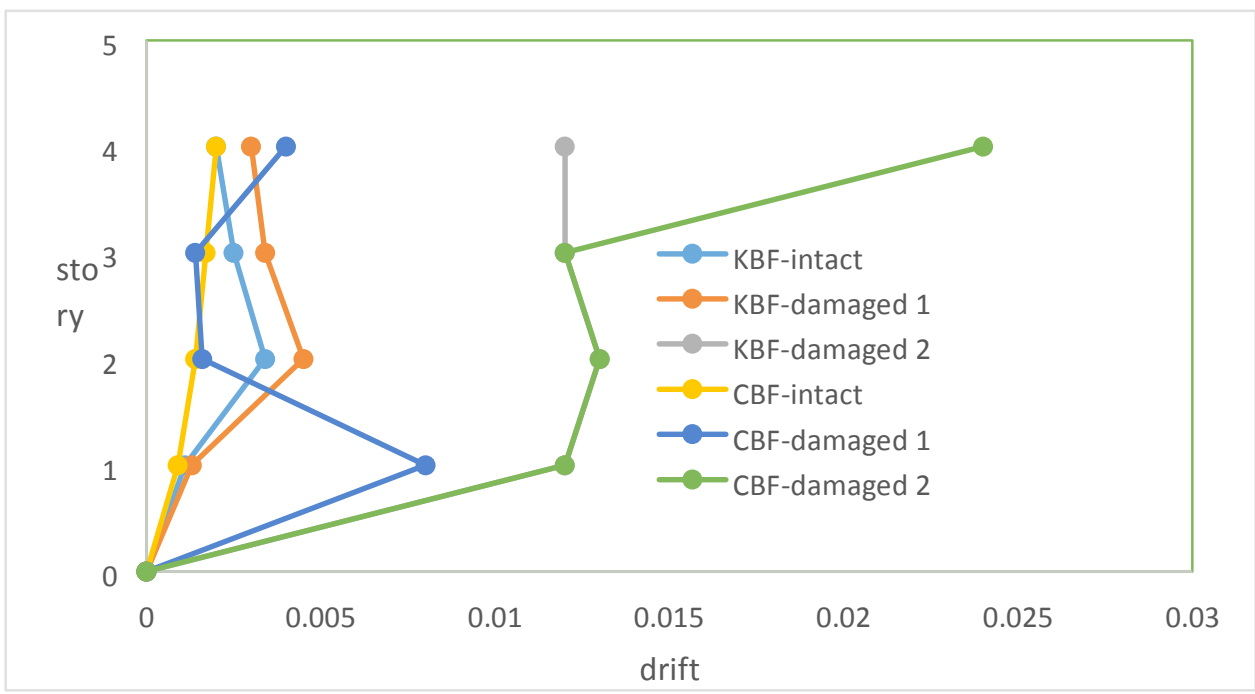

(B) 


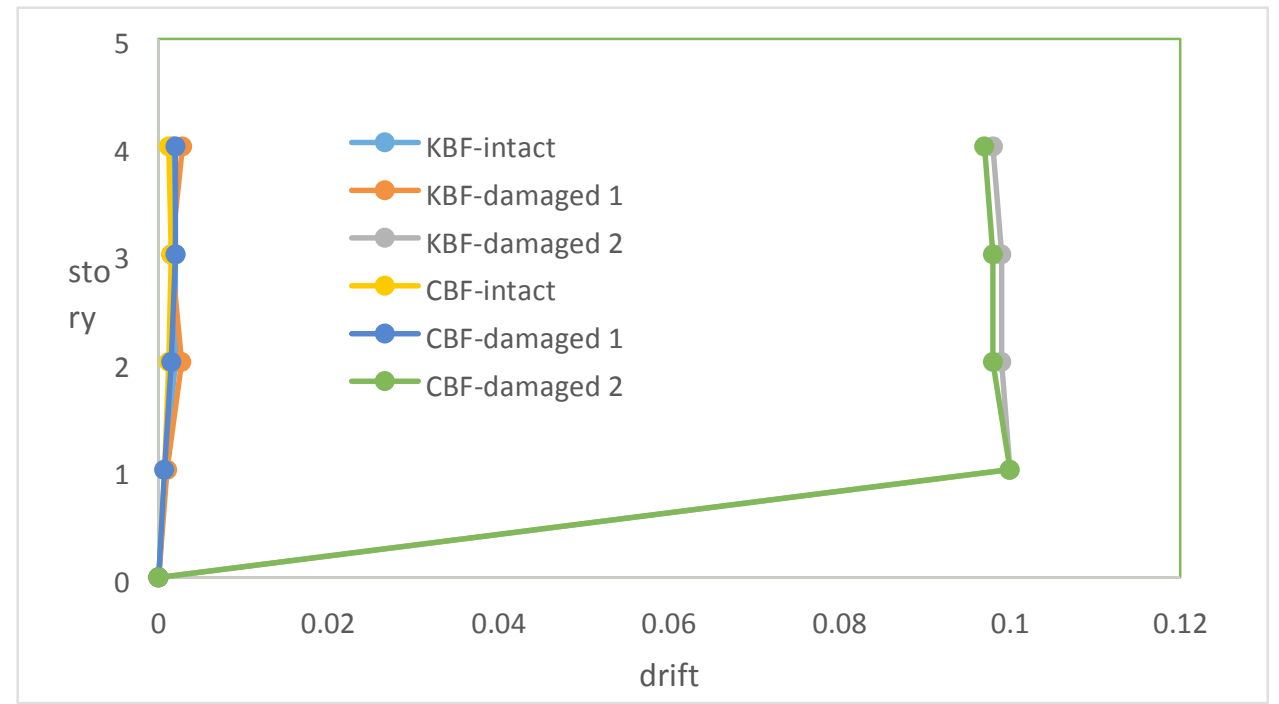

(C)

As you can see, local failure has also increased the drift of floors and damage levels of structure in other earthquakes too. These failures often cause damages in other floors and in some cases lead to general damages to the structures.

\section{CONCLUSION}

In this study, the behavior of steel structures with knee brace under gravity and seismic progressive collapse scenario was investigated. To this end, four, seven and ten-storey steel frames were designed and equipped with knee braces. To perform a better evaluation of knee braced frames behavior, some structures with concentrically braced frames (CBF) were also designed and analyzed. Results of push down analysis suggested that potential of progressive collapse under gravity load in knee braced frames has more capacity than of that in concentrically braced frames. According to the results of time history dynamic analysis, structures with $\mathrm{KBF}$ and $\mathrm{CBF}$ have great potential in the seismic progressive collapse scenario and local failure in these structures can results in their general destruction.

\section{REFERENCES}

Menchel Kfir, Progressive collapse: comparison of main standards, formulation and validation of new computational procedures, PHD thesis, 2116

Lew, H., "Best practices Guidelines For Mitigation of Building For progressive collapse",2113.

Menchel Kfir, Progressive collapse: comparison of main standards, formulation and validation of new computational procedures, PHD thesis, 2116

GSA, "Progressive collapse analysis and design guidelines for new federal office buildings and major modernization projects," General Services Administration Washington (DC, USA), 2113.

Unified Facilities Criteria, UFC-DoD, "Design of buildings to resist progressive collapse," 2115.

Straub, D. \& Faber, M. H. Risk based acceptance criteria for joints subject to fatigue deterioration', Journal of Offshore mechanics and Arctic Engineering, 2115, 027(2), 051-057.

Kapil K,El-Tawil S, Progressive collapse analysis of seismically designed steel braced frames, Journal of Constructional Steel Research ,2116095966-711.

Hartanto Wibowo, Modelling Progressive Collapse of RC Bridges during Earthquakes, CSCE Annual General Conference, 2116. 
Nielsen Jannie, Probabilistic Analysis of the Robustness of Earthquake resistant Steel Structures, Master thesis, Faculty of engineering, science and medicine, Aalborg University, 2116.

Kim J, Kim T, Assessment of progressive collapse-resisting capacity of steel moment frames, Journal of Constructional Steel Research ,2116095096-076

Karns Jesse, David L. Houghton, Macro and Micro Nonlinear Methods to Assess Progressive Collapse Potential in Steel Frame Buildings,4511 East Pacific Coast highway, Suite 011 ,Long Beach,California6111402115.

Kim J, Dawoon An, Evaluation of Progressive Collapse Potential of Steel Moment Frames Considering Catenary Action, The Structural Design of Tall and Special Buildings,2116001455-495.

Khaled Galal, Tamer El-Sawy, Effect of Retrofit Strategies on Mitigating Progressive Collapse of Steel Frame Structures, Journal of Constructional Steel Research,2101099521_530.

L.-M. Zhang and X.-L. Liu, "Learning from the Wenchuan earthquake: key problems in collapse analysis of structures," in Proceedings of the 04th World Conference on Earthquake Engineering, Chinese Association of Earthquake Engineering, Beijing, China, 2111. 